\title{
Patients with hidradenitis suppurativa have a high psychiatric disease burden: A Finnish nationwide registry study
}

\author{
Huilaja $\mathrm{L}^{1}$, Tiri $\mathrm{H}^{1}$, Jokelainen $\mathrm{j}^{2,3}$, Timonen $\mathrm{M}^{3}$, Tasanen $\mathrm{K}^{1}$ \\ 'PEDEGO Research Unit, University of Oulu; Department of Dermatology and Medical Research Center Oulu, Oulu University Hospital, Oulu, Finland \\ 2Unit of General Practice, Oulu University Hospital, Oulu, Finland \\ ${ }^{3}$ Center for Life Course Epidemiology and Systems Medicine, University of Oulu, Oulu, Finland
}

\section{INTRODUCTION}

- Hidradenitis suppurativa $(\mathrm{HS})$ is a chronic, recurrent inflammatory disease characterized by inflamed lesions in the apocrine gland-bearing areas of the skin, most commonly in the axillary, inguinal and anogenital regions (I).

- HS occurs more frequently in women than in men and has its peak prevalence among young adults $(2,3)$

- Patients with HS are known to have various comorbidities (4-6).

- In order to clarify the associations between HS and its psychiatric comorbidities at a national level, we conducted a nationwide retrospective study that included 438I patients with HS and 39554 psoriasis and 43248 melanocytic nevi patients as controls. (Table I)

\section{RESULTS}

- All the mental disorders studied were clearly more common in patients with HS than in those with psoriasis or melanocytic nevi.

- At least one mental disorder was diagnosed in $24.1 \%$ of HS patients compared with $19.1 \%$ of psoriasis patients (OR $1.34,95 \% \mathrm{Cl} 1.24-1.46)$ and $13.5 \%$ of patients with melanocytic nevi (OR 2.04,95\% CI 1.88-2.22). (Table 2)

- Major depression was the most common mental disorder in all three groups. However, it was more common in the HS group than in the psoriasis group ( $15.3 \%$ vs. $12.1 \%$, OR $1.31,95 \% \mathrm{C} 11.19-1.44)$ and in the melanocytic nevi group (8.3\%, OR 2.00, 95\% C1 1.81-2.22).

- The total prevalence psychotic disorders was $4.7 \%$ in the HS group compared with $3.3 \%$ in the psoriasis group (OR $1.46,95 \% \mathrm{CI} 1.24-1.72)$ and $1.7 \%$ the melanocytic nevi group (2.74, 95\% Cl 2.29-3.28). Specifically, "schizophrenia or schizotypal disorder" was more frequent in the HS group than in patients with psoriasis ( $2.4 \%$ vs. I.5\%, oR $\left.1.57,95 \% \mathrm{Cl}_{1} .241 .98\right)$ or in patients with melanocytic nevi (2.4\% vs.0.7\%, or 3.38, 95\% 2.59-4.39). (Table 2)

- All psychiatric disorders were more common in female than male patients with HS, with the exception of "schizophrenia or schizotypal disorder" (2.1\% in women (OR: 1.36, 95\% Cl: 0.99-1.86) vs. 2.7\% in men (OR: 1.88, 95\% Cl: 1.33-2) VS. $2.7 \%$ in men (OR: $1.88,95 \%$ Cl: $1.33-2.66)$.

- In the gender-stratified analysis the association between HS and mental disorders was significantly stronger in men than in women (OR I.46 in men vs. I.28 in women, $\mathrm{P}=0.02)$. (Figure I)

\section{CONCLUSIONS}

- Patients with HS have high psychiatric burden, even higher than patients with psoriasis

- Major depression was found in 15.3\%, anxiety disorders in $6.9 \%$ and psychotic disorders in $4.7 \%$ of HS patients.

- Both "schizophrenia or schizotypal disorder" and "bipolar disorder or manic episodes" were significantly more frequent in the HS group than in control groups

- At the moment it is largely unknown why mental disorders are so common in patients with HS, but these diseases need to be taken into account when managing with HS patients.
Table I : Characteristics of patients in HS, psoriasis and melanocytic nevi (nevi) groups.

\begin{tabular}{|c|c|c|c|}
\hline & HS & Psoriasis & Nevi \\
\hline \multicolumn{4}{|l|}{$\begin{array}{l}P a t i e n t s \\
\end{array}$} \\
\hline $\mathrm{N}$ & 4381 & 39554 & 43248 \\
\hline $\operatorname{Age}^{1}$ & $39,6( \pm 13,5)$ & $49.6( \pm 17.6)$ & $43.8( \pm 20.0)$ \\
\hline Women & $58.7 \%$ & $44.6 \%$ & $63.8 \%$ \\
\hline \multicolumn{4}{|c|}{ Non-matched patients } \\
\hline $\mathrm{N}$ & 36 & & \\
\hline \multicolumn{4}{|c|}{ Matched patients (psoriasis/nevi) } \\
\hline $\mathrm{N}^{2}$ & $4337 / 4372$ & 17318 & 17488 \\
\hline Age $^{1}$ & $39.7( \pm 13.5) / 39.6( \pm 13.5)$ & $41.6( \pm 15.2)$ & $40.5( \pm 15.7)$ \\
\hline Women & $58.4 \% / 58.7 \%$ & $58.4 \%$ & $58.7 \%$ \\
\hline
\end{tabular}

Table 2. Comorbidities in patients with $\mathrm{HS}(\mathrm{N}=4337$ for psoriasis and $\mathrm{N}=$ 4372 for melanocytic nevi) vs. matched psoriasis $(N=173 \mid 8)$ and
melanocytic nevi $(N=17488)$ controls

\begin{tabular}{|c|c|c|c|c|}
\hline Comorbidities & Group & $\mathrm{N}(\%)$ & OR $(95 \% \mathrm{CI})$ & OR $(95 \% \mathrm{CI})$ \\
\hline \multirow[t]{3}{*}{ All psychiatric disorders } & HS & $1044(24.1)$ & $1.34(1.24-1.46)$ & $2.04(1.88-2.22)$ \\
\hline & Psoriasis & $3315(19.1)$ & Reference & \\
\hline & & $2366(13.5)$ & & Reference \\
\hline \multirow[t]{3}{*}{ All psychotic disorders } & HS & $203(4.7)$ & $1.46(1.24-1.72)$ & $2.74(2.29-3.28)$ \\
\hline & Psoriasis & $566(3.3)$ & Reference & \\
\hline & Nevi & $304(1.7)$ & & Reference \\
\hline \multirow{3}{*}{$\begin{array}{l}\text { Schizophrenia or } \\
\text { disorder }\end{array}$} & HS & $103(2.4)$ & $1.57(1.24-1.98)$ & $3.38(2.59-4.39)$ \\
\hline & Psoriasis & $267(1.5)$ & Reference & \\
\hline & Nevi & $124(0.7)$ & & Reference \\
\hline \multirow{3}{*}{$\begin{array}{l}\text { Bipolar disorder } \\
\text { episodes }\end{array}$} & HS & $135(3.1)$ & $1.81(1.47-2.23)$ & $2.82(2.25-3.52)$ \\
\hline & Psoriasis & $301(1.7)$ & Reference & \\
\hline & Nevi & $196(1.1)$ & & Reference \\
\hline \multirow[t]{3}{*}{ Major depression } & HS & $663(15.3)$ & $1.31(1.19-1.44)$ & $2.00(1.81-2.22)$ \\
\hline & Psoriasis & $2099(12.1)$ & Reference & \\
\hline & Nevi & $1462(8.3)$ & & Reference \\
\hline \multirow{2}{*}{\multicolumn{2}{|c|}{$\begin{array}{l}\text { Anxiety, dissociative, stress-HS } \\
\text { related, somatoform and other Psoriasis }\end{array}$}} & $484(11.2)$ & $1.30(1.16-1.45)$ & $1.68(1.50-1.88)$ \\
\hline & & $1529(8.8)$ & Reference & \\
\hline & Nevi & $1231(7.0)$ & & Reference \\
\hline \multirow[t]{3}{*}{ Anxiety disorders } & HS & $301(6.9)$ & $1.41(1.23-1.62)$ & $1.90(1.65-2.19)$ \\
\hline & Psoriasis & $866(5.0)$ & Reference & \\
\hline & Nevi & $666(3.8)$ & & Reference \\
\hline \multicolumn{2}{|c|}{ Disorders of adult personality and HS } & $141(3.3)$ & $1.41(1.16-1.71)$ & $2.33(1.88-2.87)$ \\
\hline \multirow[t]{2}{*}{ behavior } & Psoriasis & $404(2.3)$ & Reference & \\
\hline & Nevi & $248(1.4)$ & & Reference \\
\hline
\end{tabular}

Figure I. Gender stratified odds ratios for psychiatric disorders in HS patients.

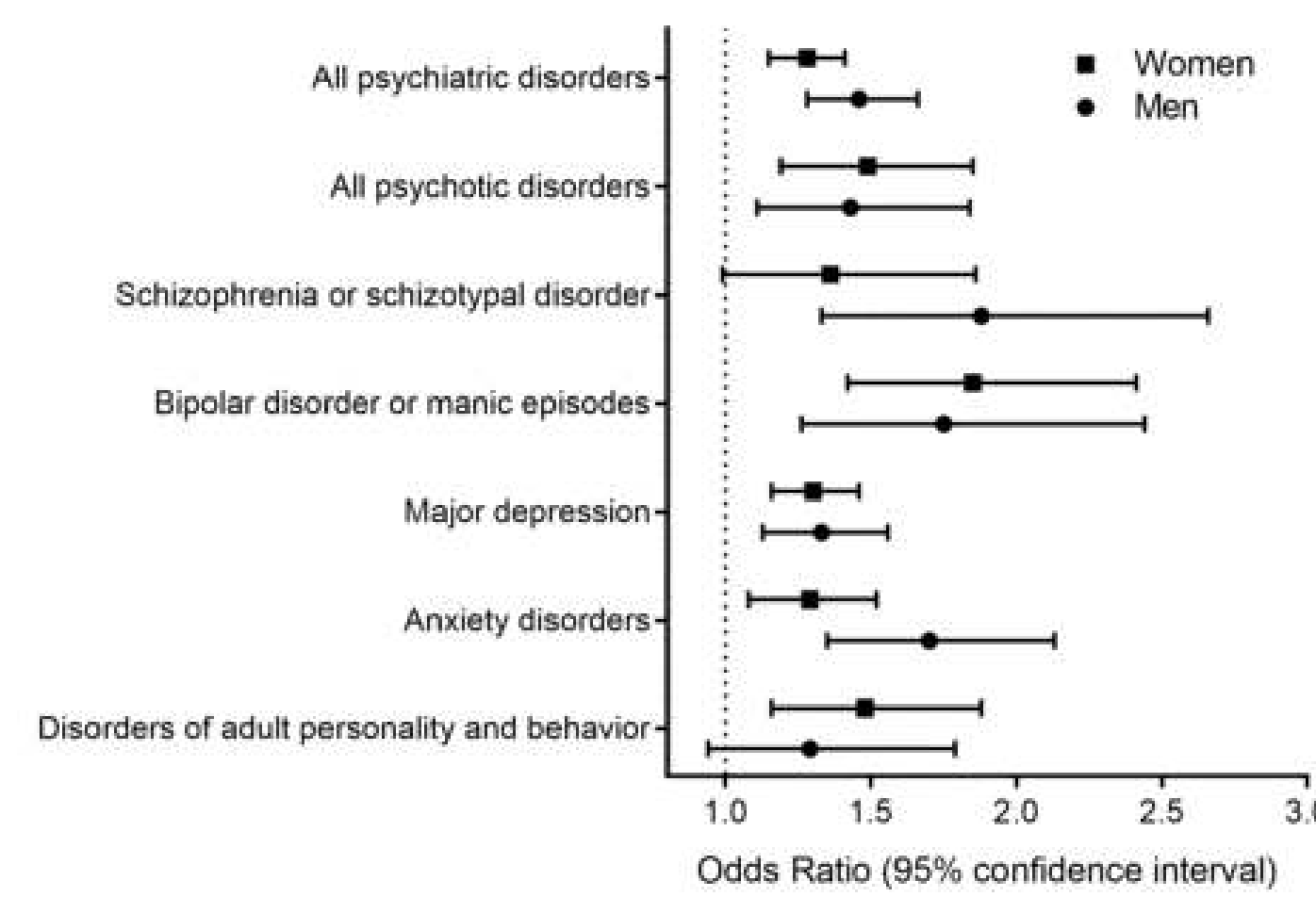

